\title{
Fuzzy Approach to Short-Term Youth Unemployment Forecast
}

\author{
Simona Hašková ${ }^{*}$ \\ ${ }^{1}$ The Institute of Technology and Business, School of Expertness and Valuation, Okružní 517/10, \\ 37001 České Budějovice, Czech Republic
}

\begin{abstract}
The practical output of the paper is the prediction of the percentage of the short-term youth unemployment in the following two consecutive years. For this purpose, the non-traditional fuzzy model of the relevant prediction task is formulated in its theoretical-methodological part, which is subsequently applied in the application part. By means of the exact tools of the fuzzy approach (fuzzy sets and inference rules for manipulation with them), the synergy, uncertainty and complexity of the values (terms) of vaguely defined linguistic variables of an economic-psychological nature represented by sets of selected macroeconomic indicators is reflected. Despite the fact that the results of the fuzzy prediction are not significantly different from the results of conventional statistical prediction, the demonstration of the approach of the case of knowledgeable expertise to the choice of the relevant fuzzy sets and the formulation of the set of inference rules can be considered as a secondary benefit.
\end{abstract}

Key words: uncertainty, unemployment, fuzzy sets, fuzzy rules

\section{Introduction to Youth Unemployment}

In the last decade youth unemployment has been in the center of attention of economists and politicians, in particular in the countries severely affected by the latest finantial cricis [1]. Regadless of the economic recession it applies that the youth unemployment rate is generally higher than adult unemployment rate. The reasons are related to the lower level of human productivity, which, ceteris paribus, entitles employers to behave rationaly and prefer adults to young people [2].

Young people are generally far more hit by the employment crises than the adults with possible severe consequences that can result in "discouraged workers" effect and social

\footnotetext{
* Corresponding author: haskova@mail.vstecb.cz
} 
exclusion from labour market. Thus, the integration of young people into the labour market is an essential objective of the European Employment Strategy [3].

In Tomić [4] analysed the key macroeconomic, microeconomic and sociological determinants of youth unemployment in 28 Member States of the European Union (EU). Its level was more pronounced in the countries with poor GDP growth, a low share of construction activity and high public debt. Futhermore, reduced mobility as a result of homeownership, perception of corruption, a high level of remittances and a lack of possibilities for young people to live outside parental homes appeared to be significant contributors as well.

The sensitivity of youth unemployment rate to economic crises differs accros the countries in dependence of e.g. the economic structure, the institutional framework, the policy-makers response at different levels, etc. [5, 6]. From the empirical point of view, the negative relationship was identified between the changes in unemployment rates and output growth in the short period known as "Okun's law". Many studies confirm this relationship for overall unemployment whereas research on youth unemployment in connection of Okun's law is not common [7]. The exeption presents the study of Dunsch [8] that examined changes in youth unemployment in Germany and Poland by means of the Okun's law while having tested whether young employees are more vulnerable to the business cycle.

The purpose of this paper is to predict the youth unemployment rate expressed as a percentage further marked as YUNE (\%), in two upcoming periods 2019 and 2021 in the Czech Republic on the basis of a historically known series of selected macroeconomic indicators of $\triangle \mathrm{IND}$ (annual change in industrial production index in \%), UNE (the total unemployment in \%), $\Delta$ GDP (the GDP growth rate in \%). The prediction tool is a fuzzy approach that, unlike standard statistical models, forms its predictive outputs within a given algorithm, which is capable to include the contribution of "soft factors" such as opinions and expertise of experts and economists.

\section{Uncertainty in Economic Predictions of Youth Unemployment}

The inaccuracy of the outcome of the prediction of the youth unemployment rate of any state is a consequence of the lack of information needed to the elimination of uncertainty we face in every non-deterministic environment [9]. This uncertainty is associated with both the inputs to the prediction model and its functioning. In the first case, we talk about "external" uncertainty resulting from the incomplete knowledge of the relevant values of known factors entering the prediction model [10]. They, together with the unknown values and therefore non-considered factors within the model, influence the future development of each macroeconomic prediction.

In the case of the uncertainty resulting from the model functioning, we talk about the "inner" uncertainty stemming from the approximate character of the formal description of the considered relationships between inputs and outputs of the prediction model [11]. In each of these cases, we can encounter the uncertainty of two different kinds. The uncertainty in terms of randomness, whose objectively identified basic statistical characteristics are known, and uncertainty in the sense of "fuzziness", which predominantly derives from the vagueness of the terms (e.g., few, little, approximately, a little, essentially, simply, complexly, significantly, analogously, etc.) occurring in the description of the situation and indicating the subjective understanding of intuitive concepts. 
Econometrics often identifies uncertainty with randomness by considering the existing uncertain alternatives as equally probable in the context of the indifference principle and as a result building the rediction models solely on the basis of the probability theory and mathematical statistics (see e.g. [12]).

However, a number of system theory authorities (see, for example, [13]) call into question the effectiveness of decision-making and management procedures based on the approximation of uncertainty with randomness. In terms of uncertainty, their works operate with the terms of linguistic variables formalized by fuzzy sets instead of the numerical values of random variables. Zadeh's work conception of terms as representatives of intuitive concepts is in line with Kahneman's conception of the functioning of the human mind (see [14]).

The aim of the paper is to present the fuzzy algorithm of the short-term prediction of the youth unemployment rate in the Czech Republic operating under conditions of inner uncertainty and formulated within Zadeh's fuzzy approach offering subjectively expected values as a viable alternative to statistically expected prediction. It deals with the fuzzy algorithm of the progression of the time series, which is preceded by a brief discussion of the basic principles of the fuzzy approach. In the application section, the fuzzy algorithm is used for the estimation of the youth unemployment in 2019 (the comparison with the published econometric forecast) and 2021 (a contribution to the paper).

\section{Methodology: Brief Introduction to the Fuzzy Approach}

The fuzzy approach can be traced in different versions of fuzzy logic, which was formed by adapting the binary numerical characteristics of the proposition operators to the interval $\langle 0,1\rangle$ [15]. The fuzzy logic performes a tool for handling of fuzzy sets, the theory of which was published by Zadeh [16].

In brief let us describe the set theory as follows (for more details see e.g. [17]): Let the set $U$ be a field of consideration or discussion. Let $\mu_{\underline{A}}$ : $U \rightarrow\langle 0,1\rangle$ be a membership function and let $\underline{A}=\left\{\left(y, \mu_{\underline{A}}(y)\right): y \in U\right\}$ be a set of all pairs $\left(y, \mu_{\underline{A}}(y)\right)$ in which the numbers $0 \leq \mu_{\underline{A}}(y)$ $\leq 1$ assign to the given $y \in U$ a membership degree of the pair $\left(y, \mu_{A}(y)\right)$ to the set $\underline{A}$. Then $\underline{A}$ is a fuzzy subset on the universe $U$. The significant characteristic of fuzzy subset $\underline{A}$ is its support $U_{\underline{A}}=\left\{y: 0<\mu_{\underline{A}}(y) \leq 1, y \in U\right\} \subset U$. In terms of fuzzy logic $\mu_{\underline{A}}(y)=\left|y \in U_{\underline{A}}\right|$. The element $y \in U$ with $\mu_{\underline{A}}(y)=0.5$ is called the crossover point in $\underline{A}$. In the case of values greater than 0.5 , the element $y$ rather belongs to $U_{\underline{A}}$, in the case of the smaller ones it rather does not belong to it [18].

In this paper, the numerical fuzzy sets are formal representations of terms of linguistic variables. For our purpose, the model with one internal and two border fuzzy sets for the terms low $(\underline{L})$, middle $(\underline{M})$, and high $(\underline{H})$ value is suitable. Interval $U$ is divided with the points $\mathrm{a}, \mathrm{b}, \mathrm{c}, \mathrm{d}$ into five sections with the following membership functions (1):

(L) $\quad \mu_{\underline{L}}(y)=1$ for $y<a$,

$\mu_{\underline{L}}(y)=(\mathrm{b}-y) /(\mathrm{b}-\mathrm{a})$ for $\mathrm{a} \leq y<\mathrm{b}$,

$\underline{\mu_{L}}(y)=0$ otherwise.

$$
\begin{aligned}
& \mu_{\underline{M}}(y)=(y-\mathrm{a}) /(\mathrm{b}-\mathrm{a}) \text { for } \mathrm{a} \leq y<\mathrm{b}, \\
& \mu_{\underline{M}}(y)=1 \text { for } \mathrm{b} \leq y<\mathrm{c}, \\
& \mu_{\underline{M}}(y)=(\mathrm{d}-y) /(\mathrm{d}-\mathrm{c}) \text { for } \mathrm{c} \leq y<\mathrm{d}, \\
& \mu_{\underline{M}}(y)=0 \text { otherwise. }
\end{aligned}
$$




$$
\begin{aligned}
& \mu_{\underline{H}}(y)=0 \text { for } y<c, \\
& \mu_{\underline{H}}(y)=(y-c) /(d-c) \text { for } c \leq y<d, \\
& \mu_{\underline{H}}(y)=1 \text { otherwise. }
\end{aligned}
$$

The role of the expert is to determine the position of the points $\mathrm{a}, \mathrm{b}, \mathrm{c}$ and $\mathrm{d}$ in the given universe $U$. In the case of their regular distribution, the courses of the functions $\mu$ are given as shown in Fig. 1 in Part 5. From it we see that the linguistic variable acquires the values at two levels: at the level of the basal values $y$ in the universe $U$ and at the level of terms (intuitive concepts) as fuzzy subsets of $\underline{L}, \underline{M}, \underline{H}$ in the universe $U$. Each of these terms is defined by its membership function $\mu_{\underline{L}}, \mu_{\underline{M}}, \mu_{\underline{H}}$ over the field of its support, which is a subset of $U$.

Another important tool of the fuzzy set theory is the rule. In our considered model with $\mathrm{n}$ input linguistic variables and one output linguistic variable it is an element $\left(\left(\underline{A}_{1, \ldots,} \underline{A}_{\mathrm{n}}\right), \underline{C}\right)$ of the relation $F \subset\left(\left\{\underline{L}_{1}, \underline{M}_{1}, \underline{H}_{1}\right\} \times \ldots \times\left\{\underline{L}_{\mathrm{n}}, \underline{M}_{\mathrm{n}}, \underline{H}_{\mathrm{n}}\right\}\right) \times\{\underline{L}, \underline{M}, \underline{H}\}$, which is a projection $F:\left(\left\{\underline{L}_{1}\right.\right.$, $\left.\left.\underline{M}_{1}, \underline{H}_{1}\right\} \times \ldots \times\left\{\underline{L}_{\mathrm{n}}, \underline{M}_{\mathrm{n}}, \underline{H}_{\mathrm{n}}\right\}\right) \rightarrow\{\underline{L}, \underline{M}, \underline{H}\}$ in the form of $F\left(\underline{A}_{1, \ldots}, \underline{A}_{\mathrm{n}}\right)=\underline{C}$, where $\underline{C} \in\{\underline{L}, \underline{M}$, $\underline{H}\}$ and $\underline{A}_{\mathrm{i}} \in\left\{\underline{L}_{\mathrm{i}}, \underline{M_{\mathrm{i}}}, \underline{H_{\mathrm{i}}}\right\}, \mathrm{i}=1, \ldots, \mathrm{n}$. The $\mathrm{n}$-tuple of terms $\left(\underline{A}_{1}, \ldots, \underline{A_{\mathrm{n}}}\right)$ is the left side of the rule, the term $F\left(\underline{A}_{1, \ldots}, \underline{A}_{\mathrm{n}}\right)$ is the right side of the rule. The relation $F$ has a maximum of $\mathrm{n}^{3}$ elements. We call it a set of inferential rules.

One of the basic concepts of the fuzzy set theory is the extension principle (in detail see [19]). Our modification of the extension principle is based on the following steps:

a) Fuzzification in which the input vector $x=\left(x_{1}, \ldots, x_{\mathrm{n}}\right)$ converts each inference rule from the set $P$ into the logical notation mode.

b) A set of partial results is a set $B=\left\{\min \left\{\min \left\{\mu_{1}\left(x_{1}\right), \ldots, \mu_{\mathrm{n}}\left(x_{\mathrm{n}}\right)\right\}, \mu_{\underline{B}}\right\}:\left(\min \left\{\mu_{1}\left(x_{1}\right), \ldots\right.\right.\right.$, $\left.\left.\left.\mu_{\mathrm{n}}\left(x_{\mathrm{n}}\right)\right\}, \mu_{\underline{B}}\right) \in P^{*}\right\}$.

c) Aggregation or summation of functions of set $B$ into a compact unit and its aggregate $\mu_{\text {agg }}$ detection; this compact unit is a fuzzy subset on the universe $V$ with $\mu_{\text {agg }}=$ $\max \left\{\min \left\{\min \left\{\mu_{1}\left(x_{1}\right), \ldots, \mu_{\mathrm{n}}\left(x_{\mathrm{n}}\right)\right\}, \mu_{\underline{B}}\right\}:\left(\min \left\{\mu_{1}\left(x_{1}\right), \ldots, \mu_{\mathrm{n}}\left(x_{\mathrm{n}}\right)\right\}, \mu_{\underline{B}}\right) \in P^{*}\right\}$.

d) Defuzzification, which transforms the result from the level of terms (the function $\mu_{\underline{A G G}}(y)$ of the fuzzy set $\left.\underline{A G G}\right)$ into $y_{0} \in Y$ in the space of numerical values of the output linguistic variable. We ascertain the numeric value $y_{0}$ as the horizontal coordinate of the center of gravity of the area under the course of the function $\mu_{\underline{A G G}}(y)$. Thus:

$$
y_{0}=\int y \cdot \mu_{\underline{\mu_{G G}}}(y) d y / \int \underline{\mu_{\underline{A G G}}}(y) d y
$$

where $\int$ is the symbol of a certain integral over the universe $Y$.

Since the resulting constant $y_{0}$ is largely the result of the subjective experience and opinions of experts who created the model, we call it a subjectively expected value.

\section{The Set of Input Variables and Assumptions}

The formulation of the fuzzy prediction model of the next time series member has its own specificity consisting of the fact that previous members of the resulting series are known (the historically measured values). Specifically, in the case of the YUNE rate prediction it is possible to evaluate the current YUNE development (decline, growth, stagnation, etc.). We also know the previous part of the baseline values of several linguistic variables, on which YUNE depends (albeit, largely vaguely). This reflects in the values of the extreme limits within which we look for the result of the prediction. 
Table 1 lists the baseline values of $\triangle \mathrm{IND}$ (annual change in industrial production index in \%), UNE (the total unemployment in \%), $\triangle$ GDP (the GDP growth rate in \%) and the output linguistic variable YUNE (the YUNE rate in \%) of the Czech Republic between 2010 and 2018 and their econometric forecasts in 2019 and 2020 [20, 21, 22, 23, 24] (highlighted columns in Tab. 1).

Table 1. Basic macroeconomic data for fuzzy predicting models of youth unemployment rate development in the Czech Republic

\begin{tabular}{|l|r|r|r|r|r|r|r|r|r|r|r|}
\hline Year & $\mathbf{2 0 1 0}$ & $\mathbf{2 0 1 1}$ & $\mathbf{2 0 1 2}$ & $\mathbf{2 0 1 3}$ & $\mathbf{2 0 1 4}$ & $\mathbf{2 0 1 5}$ & $\mathbf{2 0 1 6}$ & $\mathbf{2 0 1 7}$ & $\mathbf{2 0 1 8}$ & $\mathbf{2 0 1 9}$ & $\mathbf{2 0 2 0}$ \\
\hline$\Delta \mathrm{IND}(\%)$ & 25.7 & -2.5 & -6.3 & 0.7 & 5.1 & $-0,7$ & -0.9 & 3.0 & -3.1 & 0.3 & -0.6 \\
\hline UNE(\%) & 7.28 & 6.71 & 6.98 & 6.95 & 6.11 & 5.05 & 3.95 & 2.89 & 2.24 & 2.11 & 2.10 \\
\hline$\Delta \mathrm{GDP}(\%)$ & 2.3 & 1.8 & -0.8 & -0.5 & 2.7 & 5.3 & 2.5 & 4.4 & 2.9 & 2.4 & 2.4 \\
\hline YUNE\% & $\mathbf{1 8 . 3}$ & $\mathbf{1 8 . 1}$ & $\mathbf{1 9 . 5}$ & $\mathbf{1 8 . 9}$ & $\mathbf{1 5 . 9}$ & $\mathbf{1 2 . 6}$ & $\mathbf{1 0 . 5}$ & $\mathbf{7 . 9}$ & $\mathbf{6 . 7}$ & $\mathbf{3 . 7 4}$ & $\mathbf{3 . 7 3}$ \\
\hline
\end{tabular}

Source: Own processing.

The opinion of experts is an important specificity of the fuzzy model formulation; the experts take their knowledge and experience into account through qualified interventions in the model structure and the inference rules formulation.

The model works with the dimensionless values $u_{\Delta \mathrm{IND}}, u_{\mathrm{UNE}}, u_{\Delta \mathrm{GDP}}$ of input universes $U_{\mathrm{IIND}}, U_{\mathrm{UNE}}, U_{\triangle \mathrm{GDP}}$, or respectively with dimensionless value $y$ of output universe $Y_{\mathrm{YUNE}}$. These dimensionless input values are obtained by converting the given basal input values $x_{\triangle \mathrm{IND}}, x_{\mathrm{UNE}}, x_{\triangle \mathrm{GDP}}$ of the respective input linguistic variables into intervals $\langle 0,100\rangle$ by the formula $u=100 \cdot\left(x-x_{\min }\right) /\left(x_{\max }-x_{\min }\right)$, where $x_{\max }$, or respectively $x_{\min }$ is the highest, or respectively the lowest given value $x$ within the monitored period.

In our case, the output linguistic variable is the growth rate of the YUNE(\%) in the year immediately following the monitoring period. The conversion of the inserted basal output value $x_{\mathrm{YUNE}}$ of the universe of the output linguistic variable to the dimensionless value $y \in$ $Y_{\mathrm{YUNE}}=\langle 0,100\rangle$ (in the following text and figures $Y_{\mathrm{YUNE}}$ is shortly marked as $Y$ ) is also given by the formula $y=100 \cdot\left(x-x_{\min }\right) /\left(x_{\max }-x_{\min }\right)$, where $x_{\max }$ is the value at the end of monitoring period and $x_{\min }$ is so called "natural rate of unemployment" a priori (subjectively) expected at value of $3 \%$. For the conversion in the opposite direction $x=x_{\min }+y \cdot\left(x_{\max }-\right.$ $\left.x_{\min }\right) / 100$ applies.

\section{The Results of the YUNE Prediction}

The course of the YUNE(\%) (see Table 1) during the period 2014-2018 shows a decreasing course. In the 2019 and 2020 further decline is expected. The formulation of the predictive fuzzy model for the year 2019 is based on the characteristics of this period.

Table 2. The conversion of basal data of Table 1 relevant to the period 2014-2018 into dimensionless ones

\begin{tabular}{|c|c|c|c|c|c|}
\hline Year & 2014 & 2015 & 2016 & 2017 & 2018 \\
\hline$\Delta \mathrm{IND}(\%)$ & 100 & 29.2 & 26.8 & 74.4 & 0 \\
\hline UNE(\%) & 100 & 72.6 & 44.2 & 16.8 & 0 \\
\hline$\Delta \mathrm{GDP}(\%)$ & 7.1 & 100 & 0 & 67.8 & 14.3 \\
\hline YUNE(\%) & & & & & 100 \\
\hline
\end{tabular}

Source: Own processing. 
Thus, from last column of Table 2 the triple $(0,0,14.3) \in U_{\Delta \mathrm{IND}} \times U_{\mathrm{UNE}} \times U_{\Delta \mathrm{GDP}}$ has been created. Because of the external and internal uncertainty of the model we choose the points $\mathrm{a}, \mathrm{b}, \mathrm{c}, \mathrm{d}$ within the interval $\langle 0,100\rangle$ evenly distributed $(\mathrm{a}=20, \mathrm{~b}=40, \mathrm{c}=60, \mathrm{~d}=80)$, (see formula (1) in Part 3). Therefore, the courses of the membership functions of the converted output and all the converted inputs are identical (see Fig. 1, in which these courses are plotted above the domain of universe $Y$ of converted values of the output linguistic variable).

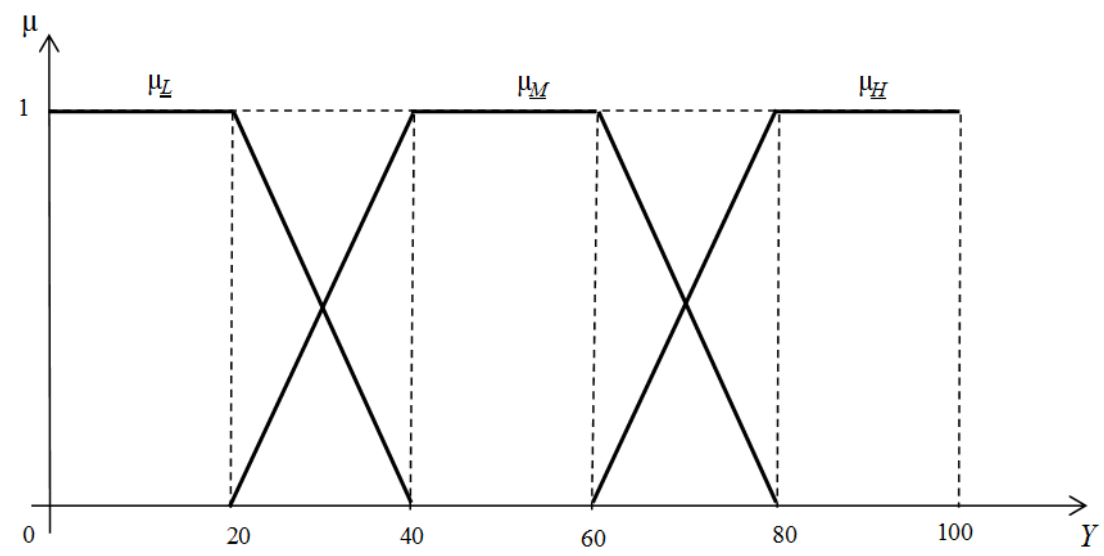

Fig. 1. Courses of the membership functions with even distribution of the points a, b, c, d within the interval values $y \in Y=\langle 0,100\rangle$

Source: Own processing.

The following fuzzification table valid for $\mathrm{i}=$ IND, UNE, GDP, whose elements are the values $\mu_{\underline{A_{i}}}\left(\mathrm{u}_{\mathrm{i}}\right)$, where index $\underline{\mathrm{A}} \in\{\underline{\mathrm{L}}, \underline{\mathrm{M}}, \underline{\mathrm{H}}\}$, is derived from the above stated equations and inequalities:

Table 3. Fuzzification table valid for $\mathrm{i}=$ IND, UNE, GDP

\begin{tabular}{|c|r|r|r|r|r|}
\hline Interval & $\boldsymbol{u}_{\mathbf{i}}<\mathbf{2 0}$ & $\mathbf{2 0} \leq \boldsymbol{u}_{\mathbf{i}}<\mathbf{4 0}$ & $\mathbf{4 0} \leq \boldsymbol{u}_{\mathbf{i}}<\mathbf{6 0}$ & $\mathbf{6 0} \leq \boldsymbol{u}_{\mathbf{i}}<\mathbf{8 0}$ & $\boldsymbol{u}_{\mathbf{i}} \geq \mathbf{8 0}$ \\
\hline$\underline{\boldsymbol{L}}_{\mathbf{i}}$ & 1 & $\left(40-u_{\mathrm{i}}\right) / 20$ & 0 & 0 & 0 \\
\hline$\underline{\boldsymbol{M}}_{\mathbf{i}}$ & 0 & $\left(u_{\mathrm{i}}-20\right) / 20$ & 1 & $\left(80-u_{\mathrm{i}}\right) / 20$ & 0 \\
\hline$\underline{\boldsymbol{H}}_{\mathbf{i}}$ & 0 & 0 & 0 & $\left(u_{\mathrm{i}}-60\right) / 20$ & 1 \\
\hline
\end{tabular}

Source: Own processing.

In the fuzzification table, only non-zero elements are taken into account, with the help of which the input vector $(0,0,14.3) \in U_{\Delta \mathrm{IND}} \times U_{\mathrm{UNE}} \times U_{\Delta \mathrm{GDP}}$ generates the set $X=\left\{\left(\underline{L}_{\Delta \mathrm{IND}}, 1\right)\right.$, $\left.\left(\underline{L}_{\mathrm{UNE}}, 1\right),\left(\underline{L}_{\Delta \mathrm{GDP}}, 1\right)\right\}$. From its three elements only one element set $L F=\{(\underline{L}, \underline{L}, \underline{L})\}$ can be created. The triad $(\underline{L}, \underline{L}, \underline{L})$ of the input fuzzy sets the projection $F$ assigns the output fuzzy set $\underline{L}$ according to the strategy of the predominant element and then applies $\mu_{A G G}(\mathrm{y})=\mu_{\underline{L}}(\mathrm{y})$ (see the highlighted course of line in Fig. 2. 


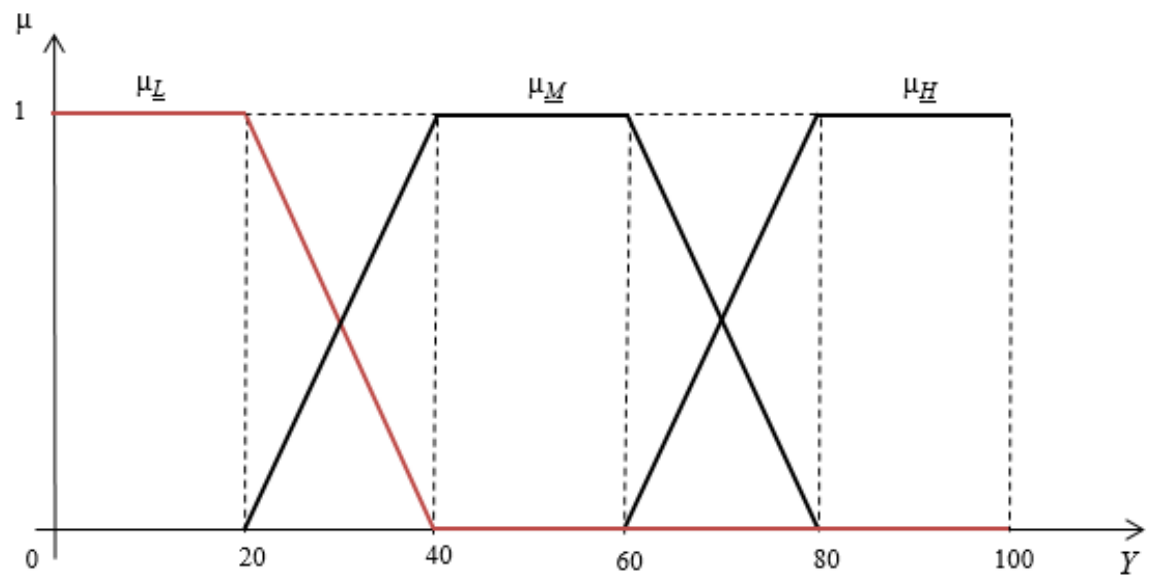

Fig. 2. The course of the membership function $\mu_{\underline{A G G}}$

Source: Own processing.

For dimensionless value $y_{0}$ given by formula (2) than holds:

$$
y_{0}=\int y \cdot \mu_{\underline{L}}(y) \mathrm{dy} / \int \mu_{\underline{L}}(y) \mathrm{dy} \approx 15.55
$$

and predicted basal value $x_{0}$ of $x_{\mathrm{YUNE}}$ for year 2019 is $x_{0} \approx 3+15.55 \cdot(6.7-3) / 100=3.57$.

The formulation of the predictive fuzzy model for the year 2021 is based on the characteristics of the period 2016-2020.

Table 4. The conversion of basal data of Table 1 relevant to the period 2016-2020 into dimensionless ones

\begin{tabular}{|c|c|c|c|c|c|}
\hline Year & 2016 & 2017 & 2018 & 2019 & 2020 \\
\hline$\Delta \mathrm{IND}(\%)$ & 36 & 100 & 0 & 55.7 & 41 \\
\hline UNE(\%) & 100 & 42.7 & 7.5 & 1 & 0 \\
\hline$\Delta \mathrm{GDP}(\%)$ & 12 & 100 & 30.5 & 0 & 0 \\
\hline YUNE(\%) & & & & & 100 \\
\hline
\end{tabular}

Source: Own processing.

Thus, from last column of Table 4 the triple $(41,0,0) \in U_{\Delta \mathrm{IND}} \times U_{\mathrm{UNE}} \times U_{\Delta \mathrm{GDP}}$ has been created. From Table 3 it is obvious that this input vector generates the set $X=\left\{\left(\underline{M}_{\Delta \mathrm{IND}}, 1\right)\right.$, $\left.\left(\underline{L}_{\mathrm{UNE}}, 1\right),\left(\underline{L}_{\Delta \mathrm{GDP}}, 1\right)\right\}$. From its three elements only one element set $L F=\{(\underline{M}, \underline{L}, \underline{L})\}$ can be created. The triad $(\underline{M}, \underline{L}, \underline{L})$ of the input fuzzy sets the projection $F$ assigns the output fuzzy set $\underline{L}$ according to the strategy of the predominant element and then applies $\mu_{A G G}(\mathrm{y})=\mu_{\underline{L}}(\mathrm{y})$ with the same highlighted course of line as in the previous case.

$$
y_{0}=\int y \cdot \mu_{\underline{L}}(y) \mathrm{dy} / \int \mu_{\underline{L}}(y) \mathrm{dy} \approx 15.55
$$

and predicted basal value $x_{0}$ of $x_{\mathrm{YUNE}}$ for year 2021 is $x_{0} \approx 3+15.55 \cdot(3.73-3) / 100=3.11$.

\section{Results Discussion and Summary}

The results of the statistical forecasts suggest that the Czech economy will appear near the state of "full employment" of young people. This refers to a combination of frictional, structural, and surplus unemployment that occurs among young people in a healthy economy. 
This, therefore, suggest (and the statictical data confirm it) that Czech economy will operate above its potential in the next 2 years if similar market conditions remain.

The fuzzy prediction of YUNE (\%) shows, in accordance to the development of the input variables, a significantly decreasing trend that does not fundamentally differs from statistical estimates.

In terms of the "quality" of the result, the fuzzy approach can be evaluated as a "more complex" method because, unlike the conventional statistical approach, it takes into account expert knowledge that projects into the selection of relevant fuzzy sets and formulation of a set of inference rules. This "quality" is a resultant consisting also of subjective attitudes and opinions, and as such can be considered as a method, which leads to a more complex informative value.

\section{References}

1. G.M. Caporale, L. Gil-Alana, Youth unemployment in Europe: Persistence and macroeconomic determinants. Comparative Economic Studies, 56(4), 581-591 (2014)

2. M. Choudhry, E. Marelli, M. Signorelli, The impact of financial crises on youth unemployment rate. Quaderni del Dipartimento di Economia, Finanza e Statistica, 79 (2010)

3. L. Grinevica, R. Kovalevs. Integration of young people into the Latvian labour market. Economics and Business, 27(1), 64-68 (2015)

4. I. Tomić, What drives youth unemployment in Europe? Economic vs non-economic determinants. International Labour Review, 157(3), 379-408 (2018)

5. M. Choudhry, E. Marelli, M. Signorelli, The impact of financial crises on youth unemployment rate. Quaderni del Dipartimento di Economia, Finanza e Statistica, 79 (2010)

6. J. O’Reilly, W. Eichhorst, A. Gábos, K. Hadjivassiliou, D. Lain, J. Leschke, S. McGuinness, L. Mýtna Kureková, T. Nazio, R. Ortlieb, H. Russell, P. Villa, Five characteristics of youth unemployment in Europe: Flexibility, education, migration, family legacies, and EU policy. Sage Open, 5(1), 1-19 (2015)

7. A. Banerji, H.H. Lin, S. Saksonovs, Youth unemployment in advanced Europe: Okun's law and Beyond. International Monetary Fund, 15 (2015)

8. S. Dunsch, Okun's law and youth unemployment in Germany and Poland. International Journal of Management and Economics, 49(1), 34-57 (2016)

9. R. Bayrak, H. Tatli, The Determinants of Youth Unemployment: A Panel Data Analysis of OECD Countries. The European Journal of Comparative Economics, 15(2), 231-248 (2018)

10. C. López-Duarte, M.M. Vidal-Suárez, External uncertainty and entry mode choice: Cultural distance, political risk and language diversity. International Business Review, 19(6), 575-588 (2010)

11. D. Caldara, C. Fuentes-Albero, S. Gilchrist, E. Zakrajšek, The macroeconomic impact of financial and uncertainty shocks. European Economic Review, 88, 185-2017 (2016)

12. M. Timmermans, R. Heijmans, H. Daniels, Cyclical patterns in risk indicators based on financial market infrastructure transaction data. De Nederlandsche Bank Working Paper No. 558 (2017) 
13. L.A. Zadeh, Fuzzy logic = computing with words. Computing with Words in Information/Intelligent Systems 1, 3-23 (1999)

14. D. Kahneman, Maps of bounded rationality: Psychology for behavioral economics. American Economic Review, 93(5), 1449-1475 (2003)

15. L. Běhounek, P. Cintula, From fuzzy logic to fuzzy mathematics: A methodological manifesto. Fuzzy Sets and Systems, 157(5), 642-646 (2006)

16. L.A. Zadeh, Outline of a new approach to the analysis of complex systems and decision processes. IEEE Transactions on systems, Man, and Cybernetics, 1, 28-44 (1973)

17. S. Hašková, P. Fiala. A fuzzy approach for the estimation of foreign investment risk based on values of rating indices. Risk Management, 21(3), 183-199 (2019)

18. D. Dubois, H. Prade, What are fuzzy rules and how to use them. Fuzzy Sets and Systems, 84(2), 169-185 (1996)

19. C. Kahraman, Fuzzy multi-criteria decision making: theory and applications with recent developments. Springer Science \& Business Media (2008)

20. Czech statistical office Industry - Time series, Industry: Index průmyslové produkce: meziroční indexy [Industrial production index: year-on-year indices] [online], Available at: https://www.czso.cz/csu/czso/pru ts (2019)

21. Ministry of Finance of the Czech Republic [online], Available at: https://www.mfcr.cz/cs/verejny-sektor/makroekonomika/makroekonomickapredikce/2019/47-kolokvium--setreni-prognoz-makroekono-35203 (2019)

22. Real GDP growth rate - volume Percentage change on previous year [online], Available at: https://ec.europa.eu/eurostat/data/database (2019)

23. Trading Economics Czech Republic Youth Unemployment Rate - Forecast [online], Available at: https://tradingeconomics.com/czech-republic/youth-unemploymentrate?embed/forecast (2019)

24. OECD [online], Available at: https://data.oecd.org/unemp/youth-unemploymentrate.htm (2019) 